\title{
Relationship between presence of vasoconstrictor activity in cerebrospinal fluid and time after subarachnoid haemorrhage from rupture of cerebral arterial aneurysms
}

\author{
T. M. HU N T, G. H. D U B O U L A Y, W. P. B L A S O, \\ D. M. C. F O R S T R, A N D D. J . B O U L L I N
}

From the MRC Unit and University Department of Clinical Pharmacology, Radcliffe Infirmary, Oxford, the Department of Radiology, National Hospital for Nervous Diseases, London, and the Department of Neurosurgery, Royal Infirmary, Sheffield

SUMMARY The relationship between clinical condition and vasoconstrictor factors in cerebrospinal fluid was studied in 19 patients for up to six weeks after subarachnoid haemorrhage. Vasoconstrictor activity was assayed biologically. Sixteen of 19 patients improved as vasoconstrictor activity declined; this pattern was not significantly influenced by surgery. Serial angiography was performed on three patients and a qualitative relationship was shown between arterial dilatation, clinical improvement, and reduced pharmacological activity.

Cerebral arterial spasm (CAS), which occurs as a consequence of aneurysmal rupture and presents itself as a pronounced constriction of one or more of the major cerebral arteries, is still thought to be responsible for considerable mortality and morbidity despite improvements in neurosurgical techniques.

The cause of pre- and postoperative CAS is believed to be the presence of a vasoactive substance which probably circulates in the cerebrospinal fluid (CSF), and acts on the adventitial surfaces of cerebral vessels. This vasoactive substance could be derived from the wall of the damaged vessel or from the breakdown of blood in the CSF (Wilkins et al., 1967).

5-Hydroxytryptamine (5-HT) and the prostaglandins have been implicated in the aetiology of CAS (Yamamoto et al., 1972; Simeone and Finall, 1975; Starling et al., 1975; Allen et al., 1976) and are known to be released from extravasated blood. 5-HT is a major constituent of platelets, and prostaglandins can be manufactured by the brain tissue of many animals and released into the CSF (Ramwell and Shaw, 1966; Horton, 1972). Both 5-HT and prostaglandins have been shown to

Address for reprint requests: Dr D. J. Boullin, MRC Clinical Pharmacology Unit, Radcliffe Infirmary, Woodstock Road, Oxford OX2 6HE. Accepted 16 January 1979 constrict cerebral blood vessels in vitro (Boullin et al., 1976), and 5-HT is capable of constricting cerebral blood vessels in vivo (Boullin et al., 1978a). According to Du Boulay et al. (1973) this vasoconstriction could be interpreted as a state of altered reactivity where there is delayed hypersensitivity of the nerve endings in the damaged vessel causing the cerebral arteries to over-react to vasoactive stimuli.

Previous experimental work has involved the use of animal models to simulate human vasospasm (Raynor et al., 1961; Echlin, 1965, 1968, 1971; Zervas et al., 1973). There have also been a number of in vitro investigations of the pharmacological responses of both cerebral and peripheral arteries of animals (Bohr et al., 1961; Wilkins et al., 1967; Neilsen and Owman, 1971).

The first attempt to investigate the pharmacology of CAS in vitro was carried out by Buckell (1964) using the isolated rat stomach fundus to detect the presence of vasoconstrictor substances in CSF from patients with spasm. Recently, we monitored the responses of the isolated rat stomach fundus to blood, cellular extracts, and CSF from subarachnoid haemorrhage patients with and without pre- or postoperative CAS (Boullin et al., $1978 \mathrm{~b})$. In the light of results obtained from this study it was decided to use the rat stomach fundus 
to investigate the possible relationship between CAS, clinical condition, and CSF vasoactivity. It has already been shown that CSF from patients with angiographic evidence of CAS contains an unidentified constrictor factor which contracts human cerebral arteries (Boullin et al., 1976) but no longitudinal investigation has ever been made.

In this study serial pre- and postoperative samples were collected from patients with subarachoid haemorrhage and assayed for vasoconstrictor activity over a period of several weeks.

\section{Patients and methods}

The subjects were 19 patients who were admitted to the Sheffield Royal Infirmary for neurosurgical treatment of cerebral arterial aneurysms. Fourteen patients were women (average age 50.8 years) and five patients were men (average age 39.6 years). Five female and one male patient were not elected for surgery.

\section{ANGIOGRAPHY}

Preoperative bilateral carotid angiography was performed at least once on all patients. In addition, postoperative angiography was carried out in cases 13, 14, and 15 .

Two alternative anaesthetic procedures were used in conjunction with angiography. Most patients had direct percutaneous puncture of the common carotid artery under general anaesthesia which involved the use of thiopentone, nitrous oxide, muscle relaxant, or fentanyl alone with moderate hyperventilation. A small number of patients underwent angiography by femoral catheterisation.

Variations in measurement of the calibre of individual intracranial arteries, measured from angiograms using two techniques (Gabrielsen and Greitz, 1970; Radü and Du Boulay, 1976), were in the range $+2 \%$ to $-10 \%$. The actual values for arterial calibre as measured on the angiograms in the current work were in the same range as that of the two groups of investigators just mentioned (see Table 5).

Procedures were performed using approximately $10 \mathrm{ml}$ of Conray 280 contrast medium (meglumine iothalamate $60 \% ; 280 \mathrm{mg} / 1$ iodine) to outline the cerebral arterial circulation. Magnification factors for the antero/posterior (A-P) and lateral projection were 1.10 and 1.08 respectively. The radiographs of each patient were subsequently compared to establish that magnification factors had been constant for any one patient. Most subjects had one angiogram but two preoperative and one postoperative angiograms were taken for each of three patients (cases 13,14, and 15). The time interval between subarachnoid haemorrhage and the first preoperative angiogram was between four and five days, but the interval between subarachnoid haemorrhage and the second preoperative angiogram was 11 days for cases 13 and 15 , and 22 days for case 14. Postoperative angiography was performed approximately seven days after surgery. Cases 13 and 15 had angiography under general anaesthesia, while case 14 had femoral catheterisation under local anaesthesia (lignocaine). The anaesthetic protocols were not varied in any individual patient.

To determine the amount of CAS present in these patients arterial measurements obtained from the first preoperative angiogram served as baseline values for each patient. Diameter changes on the two later films were expressed as a percentage of the preoperative diameters. This method of comparison allowed the degree of constriction or dilatation to be assessed with each patient acting as his or her own control. However, the degree of CAS on the first preoperative film which served as the standard could not be measured.

\section{MEASUREMENT OF CEREBRAL ARTERIAL CALIBRE}

Arterial diameters were measured after it was established that the same place could be visualised clearly on each angiographic series for any one patient. Points were chosen where the arterial walls ran parallel in the following areas

$\mathrm{C}_{2}$ : distal to the entry of the internal carotid artery into the subarachnoid space.

$\mathrm{C}_{3}$ : close to the termination of the internal carotid artery.

$\mathrm{MC}_{1}$ : close to the origin of the middle cerebral artery.

$\mathrm{MC}_{2}$ : one of the larger branches of the middle cerebral artery.

$\mathrm{AC}_{1}$ : along the pre-communicating part of the anterior cerebral artery.

$\mathrm{AC}_{2}$ : the anterior cerebral artery (pericallosal).

When one portion of the artery showed an obvious localised constriction or dilatation, three measurements were made, one of which referred to the most proximal portion (identified by the suffix "a"), one to the middle portion (identified by the suffix " $b$ "), and the last measurement to the distal portion (identified by the suffix "c"). Making several measurements along the length of the anterior or middle cerebral arterial tree provided the opportunity for recording the changes in both narrow and wide sections. It was not always possible to make all measurements.

The arteries were measured by first marking their edges with points, using a finely sharpened 
pencil and a magnifying glass with a $\times 2$ magnification. The distance between these points was measured using a magnifying glass with a $\times 4$ magnification and a graticule scaled to $0.1 \mathrm{~mm}$.

All angiograms were randomised, and measurements were made without any knowledge of the clinical outcome of the patients or the results of pharmacological tests.

\section{CLINICAL CONDITION OF PATIENTS}

The neurological condition of each patient was assessed using the modified Botterell scale of Hunt and Hess (1968) along with the Oxford classification (Adams et al., 1978) (see Table 1). Table 2 shows the Botterell scale with the equivalent Oxford gradings; evidence for onset and/or alteration of focal neurological signs was noted (see Discussion).

\section{CEREBROSPINAL FLUID COLLECTION}

Between three and five serial CSF samples were obtained from each of the 19 patients. Six patients were not operated on, and one patient (case 10) only had CSF collected postoperatively. Pre- and postoperative CSF samples were obtained by lumbar puncture, while CSF taken at operation was removed from the ventricles. The interval between the day of subarachnoid haemorrhage

\section{Table 1 Oxford neurological classification}

\begin{tabular}{ll}
\hline Grades & Criteria \\
\hline 20 & Fully alert, orientated, not confused \\
18 & Alert, grossly orientated but slightly confused \\
16 & Drowsy \\
14 & Partially disorientated, restless, severe headache \\
12 & Difficult to rouse, grunts, disorientated \\
10 & Very drowsy, rousable to pain \\
8 & Purposive response to pain \\
6 & Flexes to pain, non-purposive \\
4 & Extends to pain, non-purposive \\
2 & Reflex response to pain \\
0 & No response to pain \\
\hline
\end{tabular}

Table 2 Modified Botterell neurological classification of Hunt and Hess (1968)

\begin{tabular}{lll}
\hline Grades & Criteria & $\begin{array}{l}\text { Equivalent } \\
\text { Oxford grading }\end{array}$ \\
\hline I & $\begin{array}{l}\text { Asymptomatic or minimal headache and } \\
\text { slight nuchal rigidity } \\
\text { Moderate to severe headache, nuchal } \\
\text { rigidity, no neurological deficit } \\
\text { Drowsiness, confusion or mild focal } \\
\text { di }\end{array}$ & $=18,19$ \\
III & $\begin{array}{l}\text { Stupor, moderate to severe hemiparesis, } \\
\text { possible early decerebrate rigidity, and } \\
\text { vegetative disturbances } \\
\text { Deep coma, decerebrate rigidity, } \\
\text { moribund appearance }\end{array}$ & $=11-7$ \\
V & $=6-0$ \\
\hline
\end{tabular}

and the first CSF collection varied from two to 18 days. Case 16 was an exception, the first CSF sample being collected 38 days after subarachnoid haemorrhage. Thereafter, two to four samples were collected at approximately two to 16 day intervals. The CSF was not centrifuged but was frozen at $-20^{\circ} \mathrm{C}$ immediately after collection and only thawed at the time of testing on the rat stomach fundus.

PREPARATION OF RAT STOMACH FUNDUS

The setting up of the rat stomach fundus has been described by Boullin et al. (1978b). Electronically amplified isotonic muscle responses were recorded using the transducer system of Boullin et al. (1976) without further modification.

Fundal strips were used only if the contraction produced by 1-4 $\mu \mathrm{mol} / 1 \mathrm{PGF}_{2 a}$ or $\mathrm{PGE}_{2}$ was a full scale response $(200 \mathrm{~mm})$ on the Teckman recorder $(5 \mathrm{mV} / \mathrm{mm}$ tissue response). Constrictor factor activity was expressed in units of contractile or relaxing activity. One unit of contractile activity is equivalent to $50-200 \mathrm{nmol} / 1 \mathrm{PGF}_{2 a}$ or $\mathrm{PGE}_{2}$ (a muscle response of $5 \mathrm{mV} / \mathrm{mm}$ ).

The prostaglandins were dissolved in $2 \%$ ethanol to give a stock solution of 1 to $10 \mathrm{mmol} / 1$ and then diluted with Krebs solution. The final concentration of ethanol in the stock solution was $0.002 \%$; this did not affect the responses of the rat stomach fundus.

After drug-induced responses, $1.0 \mathrm{ml}$ of CSF obtained from each of the 19 subarachnoid haemorrhage patients was applied to the preparation and the number of units of activity measured.

\section{NUMBER OF EXPERIMENTS}

Ninety-one per cent of CSF samples were tested two to six times; the remainder were tested only once.

\section{Results}

Figure 1 demonstrates the relationship between CSF vasoconstrictor activity and time of collection after subarachnoid haemorrhage, and shows a generalised temporal decline in constrictor activity.

Although five patients had high constrictor factor values on the first day of testing (cases 1, $2,13,14$, and 15) these all showed a decline in constrictor activity with time. Three patients showed little or no constrictor activity throughout the period of study (cases 4, 6, and 16), and CSF from two patients (cases 8 and 11) had a relaxing effect on the smooth muscle preparation. A group 


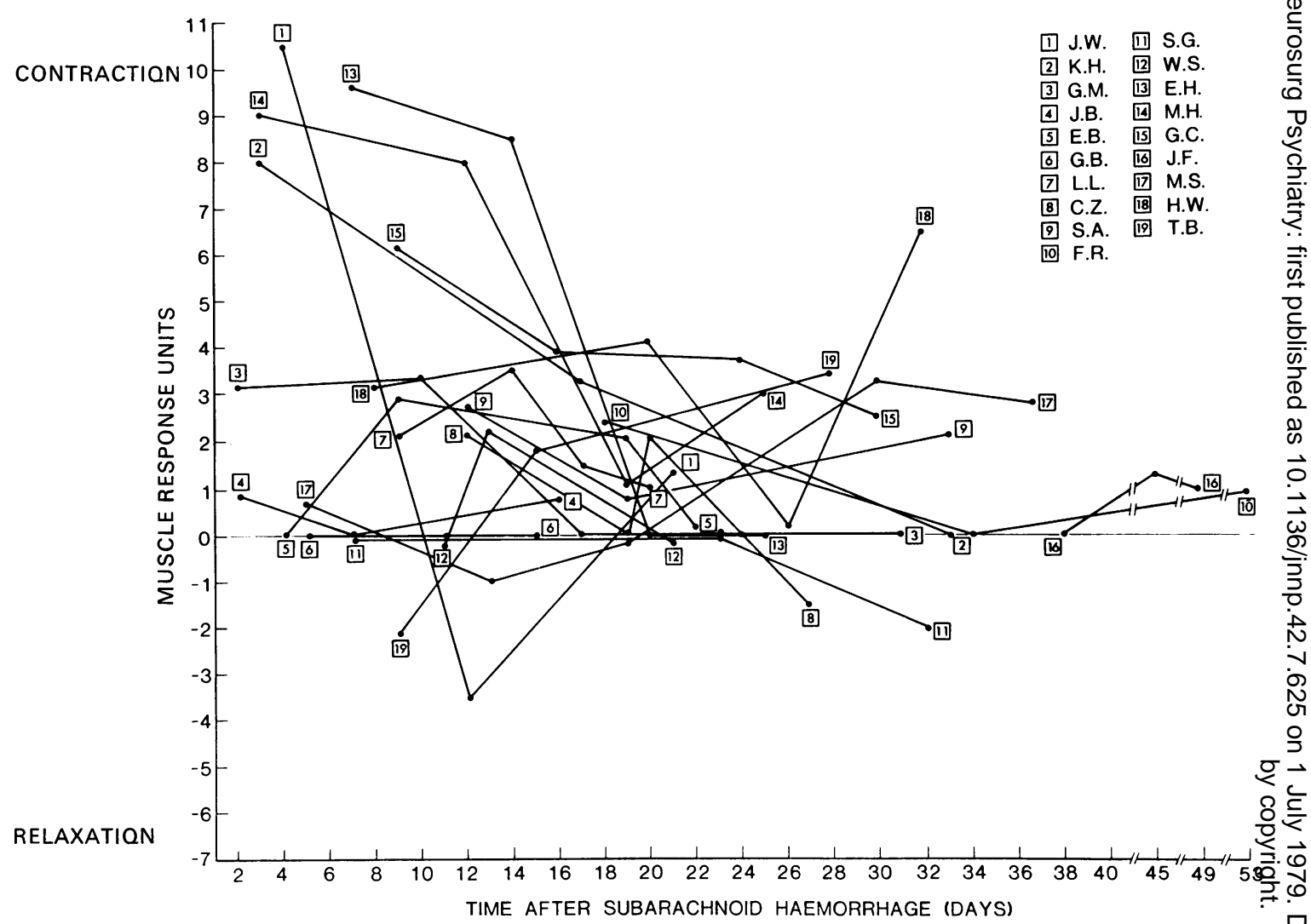

Fig. 1 Constrictor factor activity of CSF in relation to time after subarachnoid haemorrhage. Activity was assayed on the rat stomach fundus. Movements were recorded isotonically by a transducer and displayed on a single channel potentiometric recorder. Abscissa scale shows time, ordinate scale shows amplified change in tissue length measured in fundus units. One response unit $(5 \mathrm{mV} / \mathrm{mm})$ is equivalent to the response produced by 50-200 nmol/l of PGE or PGF s $_{2}$ (see text).

of six subjects had intermediate values for constrictor activity and can be subdivided into those showing an increase followed by a decrease (cases 5,7 , and 12), a decrease followed by an increase (case 9), or a continual decline (cases 3 and 10).

Finally, three patients (cases 17, 18, and 19) showed a consistent increase in constrictor activity over periods of up to four and a half weeks after subarachnoid haemorrhage but all three cases had some clinical complication. In case 17 constrictor activity increased at a time when angiography showed CAS (day 22), and there was clinical and computerised tomographic evidence of cerebral infarction. Surgery was not attempted and although the level of arousal was good, residual neurological deficit persisted on discharge to the referring centre.

Case 18 was complicated by hydrocephalus with delayed disappearance of red blood cells from the CSF. Angiography on day 7 showed CAS, while constrictor activity was high in all CSF samples except on day 26. Surgery was not attempted, and the patient was removed to the referring hospital 44 days after subarachnoid haemorrhage. Thereafter clinical improvement was slow.

Of these three only case 19 underwent neurosurgery. A preoperative CSF assay showed the presence of a relaxing factor and on day 9 there was no angiographic spasm. On day 10 there was a rapidly developing hemiplegia suggesting a rebleed from an aneurysm. In spite of this complication surgery was successful, although postoperative haemorrhage occurred. This may have accounted for the increased constrictor factor activity postoperatively. In any event clinical improvement was good. 
EFFECTS OF SURGERY

Figure 2 shows the data on constrictor factor activity after subarachnoid haemorrhage in the 13 patients who had neurosurgery for clipping an aneurysm. The results are presented in relation to the timing of surgery which has been synchronised for all patients. The interval between subarachnoid haemorrhage and surgery cannot be deduced from Fig. 2 because CSF samples were not collected on the day of bleeding.

Only three patients showed an increase in constrictor activity postoperatively (cases 1,9 , and 19) but in no case was it substantial, and in two of these patients (cases 1 and 9) postoperative constrictor factor values never exceeded those obtained on the first day of testing after subarachnoid haemorrhage. For the remaining 10 patients, surgical intervention did not appear to influence the temporal decline in constrictor factor activity.

In 11 of the 13 patients illustrated in Fig. 2, the preoperative and postoperative values for constrictor activity were compared (case 10 had no preoperative samples and the last CSF sample from case 14 was taken at the time of surgery). Table 3 shows that there was no significant difference between the two sets of data.

\section{CORRELATION BETWEEN CONSTRICTOR FACTOR}

ACTIVITY AND ANGIOGRAPHIC SPASM

Of the 19 patients studied, more than one series of angiographic measurements was performed on only three (cases 13,14 , and 15). The measurements of arterial diameter $(\mathrm{mm})$ as displayed on the angiograms are shown in Table 4. These three patients demonstrated a qualitative relationship between cranial vessel relaxation and diminished constrictor factor activity. These changes were concurrent with clinical improvement and are dealt with below.

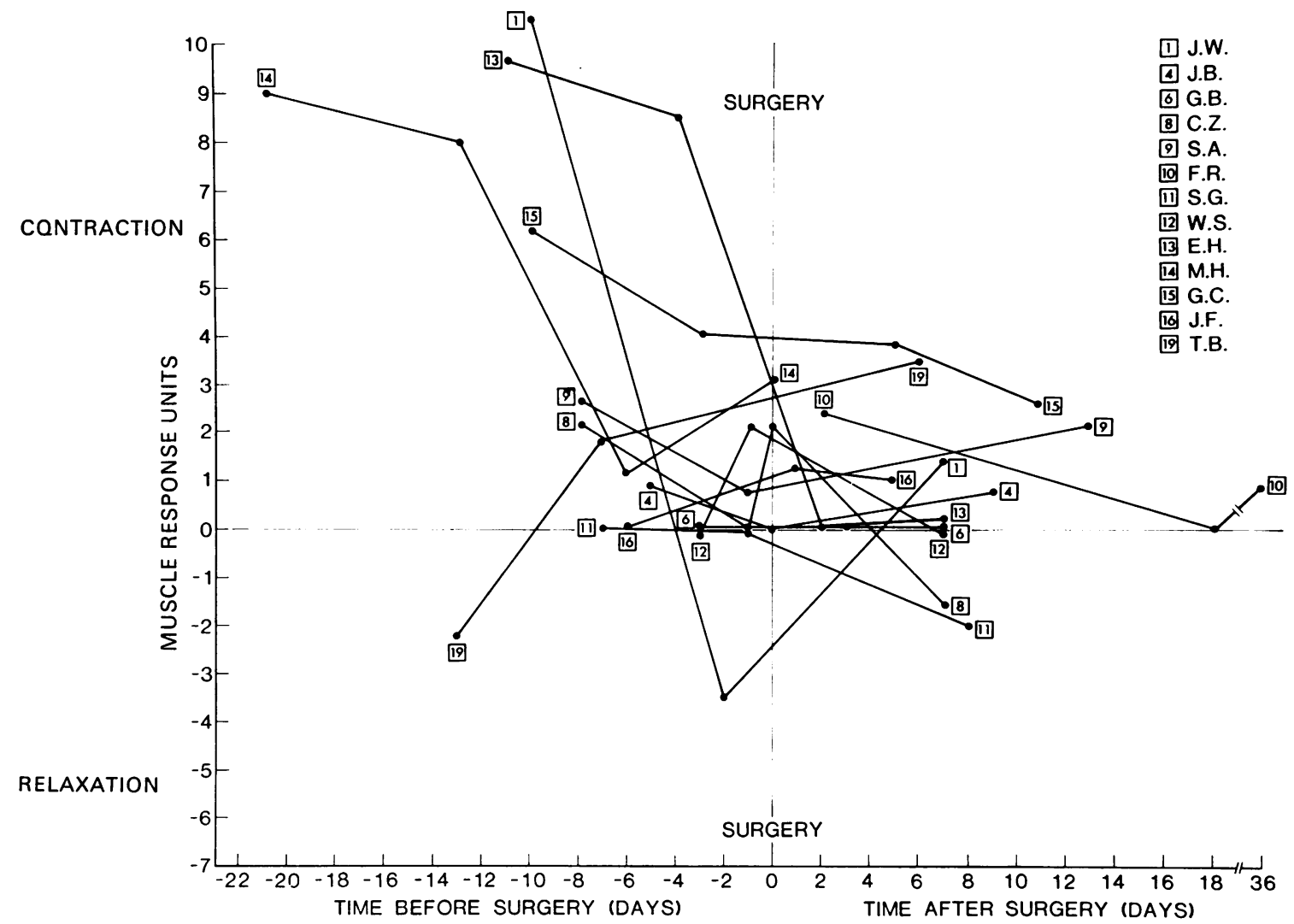

Fig. 2 Relationship between constrictor factor activity in CSF and timing of surgery. Data are the same as in Fig. 1 but only for those patients who underwent microneurosurgery. The timing of surgery has been synchronised for all subjects. The time interval between bleeding and surgery cannot be deduced from this figure. Responses were recorded isotonically as described in Fig. 1 . 
Table 3 Constrictor factor activity of pre-and postoperative CSF samples from subarachnoid haemorrhage patients

\begin{tabular}{lll}
\hline \multirow{2}{*}{ Case } & \multicolumn{2}{c}{ Constrictor factor activity } \\
\cline { 2 - 3 } & Before surgery & After surgery \\
\hline 1 & -3.5 & 1.4 \\
4 & 0.83 & 0.75 \\
6 & 0.0 & 0.0 \\
8 & 0.0 & -1.6 \\
9 & 0.75 & 2.0 \\
11 & 0.0 & -2.0 \\
12 & 2.0 & 0.0 \\
13 & 8.6 & 0.0 \\
15 & 4.0 & 3.8 \\
16 & 0.0 & 1.25 \\
19 & 1.96 & 3.4 \\
Mean & 1.33 & 0.81 \\
\hline SEM & 0.91 & 0.55 \\
\hline
\end{tabular}

These results were analysed using Student's paired $t$ test. $N=11, t$ value $=0.4808$, degrees of freedom $=20,-=$ relaxation. Values for individual patients are the mean of one to six tests (see text).

\section{Case 13}

Figure 3 shows cerebral vessel calibre (ordinate) as seen on a right oblique film plotted against days after subarachnoid haemorrhage (abscissa). The first angiogram was taken on day 7 and acts as the standard to which subsequent films taken on later days can be compared. By the time the second and third angiograms had been taken most vessels displayed varying degrees of dilatation. The proximal vessels all showed dilatation, the narrowest segments becoming most obviously wider. Constriction was only seen to occur in arteries distal to the narrow segments and was generally of a much slighter degree than dilatation. Constrictor factor activity during this period dropped from 9.6 units on day 7 to 8.6 units on day 14, with zero values on days 20 and 25 . Clinically this patient improved steadily during this same period of hospitalisation (Oxford/Botterell grades II, 16 to I, 20).

\section{Case 14}

Case 14 showed a similar clinical pattern to that of case 13 with nearly all the major cerebral vessels demonstrating a tendency towards relaxation by the second angiogram (Fig. 4). The vessels which appeared to be constricted on day 20 when the second angiogram was taken were slowly returning to baseline values by the time the third angiogram was taken on day 31 , so that only the distal parts of the anterior cerebral artery became significantly narrower between angiograms 2 and 3. The angiographic picture was paralleled by clinical improvement (Oxford/Botterell grades IV, 10 to I, 20) and a decrease in constrictor factor values from 9.0 units on day 4 to 3.0 units on day 25.

No CSF was obtained during the postoperative period, the last sample obtained was taken at time of surgery from the site of the aneurysm.

\section{Case 15}

Changes in arterial calibre were measured using an A-P film and an oblique film (Fig. 5).

Again, between angiograms 1 and 2 the same pattern as found in cases 13 and 14 was repeated. The second preoperative angiogram demonstrated major vessel relaxation; simultaneously the clinical condition improved (Oxford/Botterell grades III, 12 to II, 18) and constrictor factor activity decreased from 6.1 units on day 9 to 2.5 units on day 30 . These trends continued postoperatively, except that some branches of proximal vessels became considerably dilated. Dis-

Table 4 Calibre $(\mathrm{mm})$ of cerebral arteries of subarachnoid haemorrhage patients who underwent serial angiography

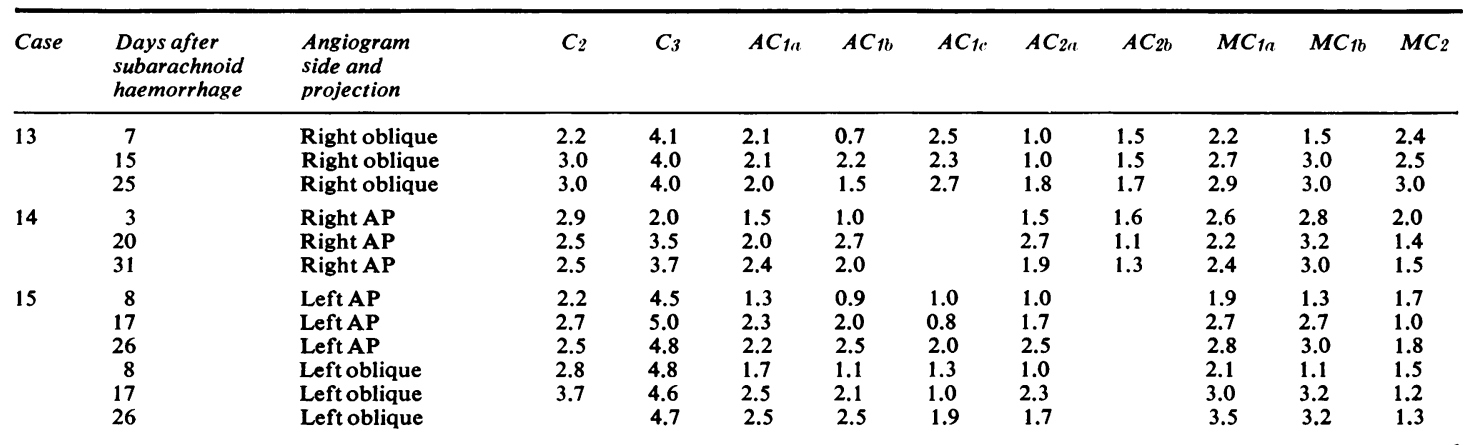

$\mathrm{C}_{2}=$ intracranial carotid artery; $\mathrm{C}_{3}=$ termination of carotid artery; $\mathbf{M C}_{1}=$ main trunk middle cerebral artery; $\mathbf{M C} \mathbf{C}_{2}=$ middle cerebral artery branch; $\mathbf{A C} \mathbf{C}_{\mathbf{1}}=$ pre-communicating anterior cerebral artery; $\mathbf{A C}_{\mathbf{2}}=$ pericallosal artery; $\mathbf{A P}=$ anteroposterior.

Values were obtained by direct visual measurement of arterial calibre as described in Methods. 


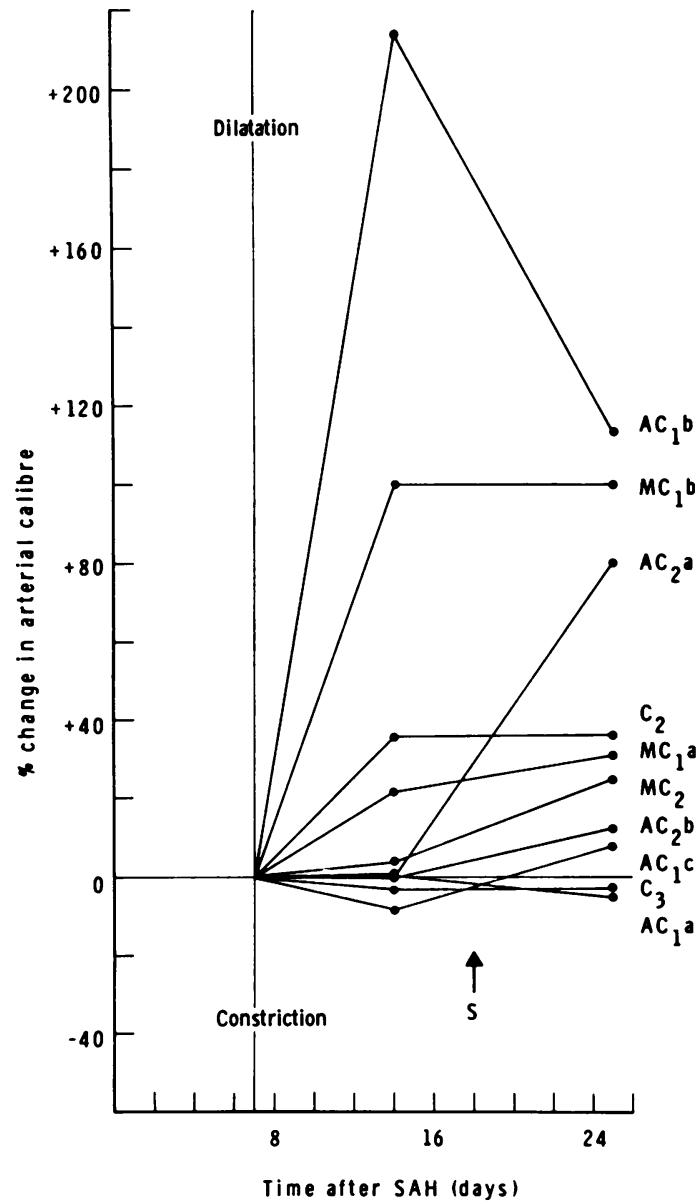

Fig. 3 Changes in calibre of proximal and distal cerebral arteries of case 13 after subarachnoid haemorrhage. Abscissa scale shows time; ordinate scale shows changes in arterial diameter expressed as a percentage change of the first angiogram (see Results). $C_{2}=$ intracranial carotid artery, $C_{3}=$ termination of carotid artery, $M C_{1}=$ main trunk middle cerebral artery, $M C_{2}=$ middle cerebral artery branch, $A C_{1}=$ pre-communicating anterior cerebral artery, $A C_{2}=$ pericallosal artery, suffix $a, b, c=$ sequential parts of named artery having initially, different calibres.

tal vessels showed a strong tendency to further dilatation.

This patient made an uneventful postoperative recovery.

\section{Discussion}

We have recently reported the presence of an unidentified vasoconstrictor factor in single CSF

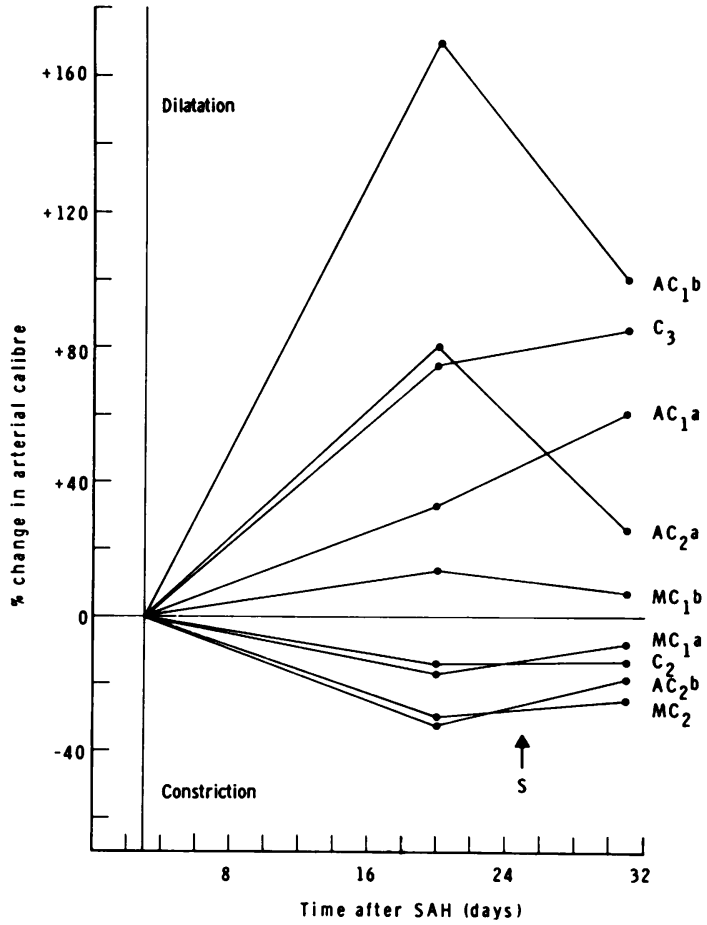

Fig. 4 Changes in calibre of proximal and distal cerebral arteries of case 14 after subarachnoid haemorrhage. Data plotted in the format given in Fig. 3 with same symbols.

samples from subarachnoid haemorrhage patients with CAS. The present investigation is the first to involve longitudinal collection and testing of CSF from subarachnoid haemorrhage patients over a prolonged period covering the normal duration of pre- and postoperative CAS .

Weir et al. (1978) have analysed single angiograms from a large number of subarachnoid haemorrhage patients and found that spasm can develop within hours of the bleed, reach a peak after one week, and disappear after two weeks. In reviewing earlier quantitative attempts to assess vasospasm, Weir et al. (1978) point out that prolonged spasm lasting three to four weeks (Allcock and Drake, 1965) is probably caused by repeated subarachnoid haemorrhage. Our results generally agree with these views on the duration and intensity of vasospasm.

Sixteen of the 19 patients demonstrated a generalised temporal decline in constrictor factor activity after subarachnoid haemorrhage (Fig. 1), and in 10 out of 13 patients surgical intervention did not appear to influence either the incidence or the intensity of cerebral vasospasm (Fig. 2). 


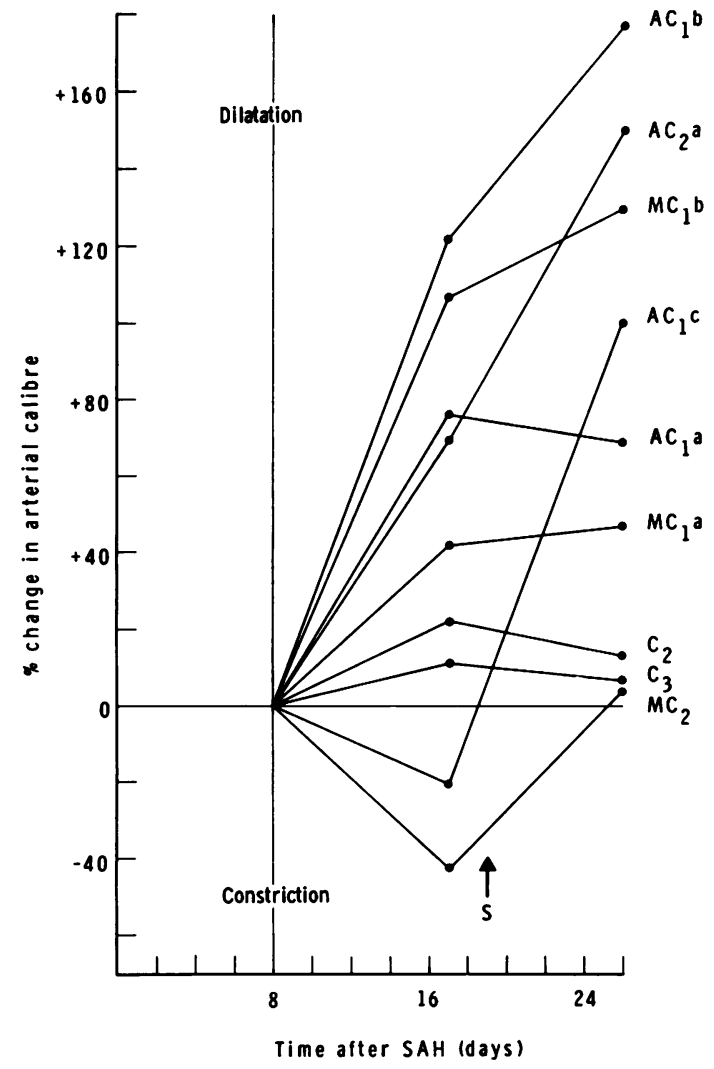

(a)

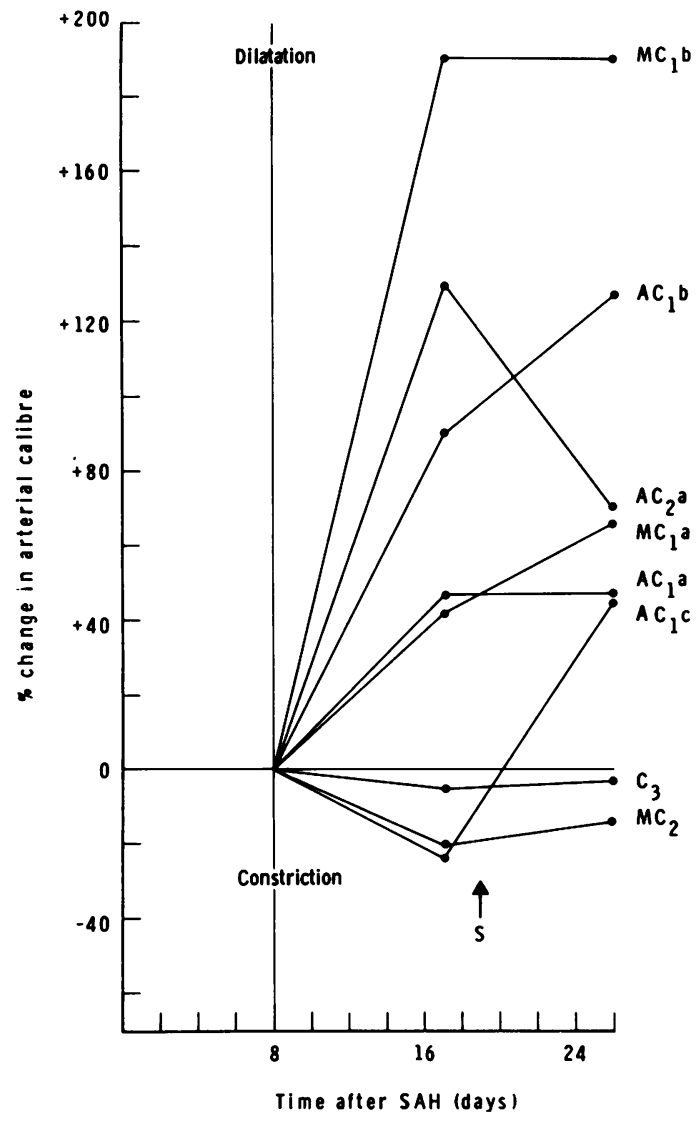

(b)

Fig. 5 Changes in arterial calibre after subarachnoid haemorrhage for case 15. Data plotted in the format and with symbols as in Fig. 3. (a) Arterial calibre obtained from a left AP angiogram. (b) Data obtained from a left oblique angiogram.

However, cases 17,18 , and 19 did not conform to this pattern and their CSF samples showed a consistent rise in constrictor factor activity after subarachnoid haemorrhage. Case 19 was selected for surgery and constrictor factor activity continued to rise postoperatively. In these three subjects clinical evidence of focal brain damage was accompanied by increased constrictor factor activity in the CSF. As there was no overt evidence of repeated haemorrhage we do not know the cause of the focal neurological signs, but this could have been the result of decreased arterial blood flow in association with vasospasm. Their values for constrictor factor activity were lower than those of Blaso and Boullin (1978) in patients that died with CAS (see below). None of the patients in the current study died. Weir et al. (1978) found that the patients with greatest vaso- spasm had a significantly higher mortality than the others, but unlike the present study these authors assessed vasospasm only by angiography and not angiography plus pharmacological assay. In any event the relationship between constrictor factor activity and prognosis is not simple.

In addition to the vasoconstrictor factor we have previously detected an unidentified "relaxing substance" in CSF from patients with subarachnoid haemorrhage (Boullin et al., 1978b). Furthermore, some of the CSF samples in this study relaxed the rat stomach fundus, and this relaxation could be consistently reproduced with a number of CSF samples (Fig. 1) and was not influenced by surgery (Fig. 2). Constrictor factor activity is only one of a number of factors influencing the prognosis after subarachnoid haemorrhage, but in this study low constrictor factor activity and a 
small degree of spasm were invariably associated with clinical improvement.

The apparent negative effect of surgical intervention on constrictor factor activity shown in our study agrees with Du Boulay (1963) and Bergvall et al. (1973) who measured the diameters of proximal cerebral vessels in approximately 50 patients and found that there was a progressive increase in arterial constriction between the fourth and seventh day after subarachnoid haemorrhage, but all arterial diameters returned to within one standard deviation of normal by day 13 .

The effect of surgery on the vessel diameter and constrictor factor activity in our study cannot be determined accurately because of the delay between surgery, angiography, and lumbar puncture. In the three patients who had serial angiography (cases 13,14, and 15) there seemed to be a qualitative relationship between cranial vessel relaxation, clinical improvement and diminished pharmacological activity of the CSF (Figs. 3, 4, 5).

From this small study we may postulate that as constrictor factor activity decreases. clinical condition improves and cerebral arterial spasm gradually disappears. Our recent work with subarachnoid haemorrhage patients from the Oxford area also supports this view. The results show that only patients with high CSF activity had angiographic evidence of severe spasm associated with a deterioration of the clinical condition (Blaso, 1978; Blaso and Boullin, 1978; Boullin and Blaso, 1978). It is worth noting that none of the Sheffield patients died and none of them had high constrictor factor activity, and the degree of spasm rarely exceeded $50 \%$ constriction, compared with the calibre of arteries of normal subjects made by two other groups (Table 5). Blaso and Boullin (1978) observed much greater spasm in patients dying of CAS. Consequently the current data support the view that a good prognosis is

Table 5 Comparison of arterial calibre of human vessels

\begin{tabular}{lccc}
\hline Author & \multicolumn{3}{l}{ Arterial calibre $(\mathrm{mm})$} \\
\cline { 2 - 4 } & $\begin{array}{l}\text { Internal } \\
\text { carotid }\end{array}$ & $\begin{array}{l}\text { Middle } \\
\text { cerebral }\end{array}$ & $\begin{array}{l}\text { Anterior } \\
\text { cerebral }\end{array}$ \\
\hline $\begin{array}{l}\text { Present work* } \\
\text { Radü and }\end{array}$ & $2.2-2.9$ & $1.3-2.8$ & $0.7-2.5$ \\
Du Boulay (1976) & 4.0 & 2.8 & 2.4 \\
Gabrielsen and & 4.6 & 3.8 & 3.0 \\
Greitz (1970)+ & 0.46 & -0.43 & 0.5 \\
\hline
\end{tabular}

* Range of observations obtained in first angiogram taken three to eight days after subarachnoid haemorrhage in cases 13-15 (Table 4).

+Mean values from 10 normal subjects.

$\ddagger$ Mean values $\ddagger$ SD from 156 normal subjects. associated with moderate spasm and low values for constrictor factor activity.

From the practical viewpoint we may ask the question "is measurement of constrictor factor activity in CSF of subarachnoid haemorrhage patients of clinical value?"

It is practical to assay the constrictor factor activity of CSF from such patients using the rat stomach fundus which acts as a diagnostic indicator of cerebral arterial spasm. When a combination of high constrictor activity plus angiographic evidence for CAS (exceeding 50\% decrease in arterial calibre, Blaso and Boullin, 1978) occurs, patients are at a higher risk than those with lower constrictor factor activity and little CAS on angiography.

The next step from the viewpoint of research into the aetiology of CAS is to identify the vasoconstrictor substances responsible for constrictor factor activity on the rat stomach fundus and human basilar artery in vitro, and we are now attempting this. We are also investigating the effects of substances which cause vasodilatation of cerebral arieries, including propranolol (Boullin and Mohan, 1977) dopamine (Boullin et al., 1977), and the recently observed vasodilator prostaglandin prostacyclin (Boullin et al., 1979).

\section{References}

Adams, C. B. T., Fearnside, M. R., and O'Laoire, S. A. (1978). An investigation with serial angiography into the evolution of cerebral arterial spasm following aneurysm surgery. Journal of Neurosurgery, 49, 805-815.

Allcock, J. M., and Drake, C G. (1965). Ruptured intracranial aneurysms-the role of arterial spasm. Journal of Neurosurgery, 22, 21-29.

Allen, G. S., Gross, C. J., French, L. A., and Chou, S. N. (1976). In vitro contractile activity of vasoactive agents including human CSF on human basilar and anterior cerebral arteries. Journal of Neurosurgery, 44, 594-600.

Bergvall, U., Steiner, L., and Forster, D. M. C. (1973). Early pattern of cerebral circulatory disturbances following subarachnoid haemorrhage. Neuroradiology, 5, 24-32.

Blaso, W. P. (1978). Pharmacological properties of cerebrospinal fluid after subarachnoid haemorrhage. MSc Thesis: Oxford University.

Blaso, W. P., and Boullin, D. J. (1978). Vasoconstrictor activity of cerebrospinal fluid from patients with cerebral arterial spasm. Journal of Physiology, 282, p. 39.

Bohr, D. F., Goulet, P. L., and Taquini, A. C., (1961). Direct tension recording from smooth muscle of resistance vessels from various organs. Angiology, $12,478-485$. 
Boullin, D. J., Adams, C. B. T., Mohan, J., Green, A. R., Hunt, T. M., Du Boulay, G. H., and Rogers, A. T. (1977). Effects of intracranial dopamine perfusion: behavioural arousal and reversal of cerebral arterial spasm following surgery for clipping of ruptured cerebral aneurysms. Proceedings of the Royal Society of Medicine, 70, Supplement 2, 5570.

Boullin, D. J., and Blaso, W. P. (1978). Pharmacological vasoactivity of cerebrospinal fluid correlates with cerebral arterial spasm and clinical deterioration after subarachnoid haemorrhage. Federation Proceedings, 37, p. 821.

Boullin, D. J., Bunting, S., Blaso, W. P., Hunt, T. M., and Moncada, S. (1979). Responses of human and baboon arteries to prostaglandin endoperoxides and biologically generated and synthetic protacyclin: their relevance to cerebral arterial spasm in man. British Journal of Clinical Pharmacology, 7, 139147.

Boullin, D. J., Du Boulay, G. H., and Rogers, A. T. (1978a). Aetiology of cerebral arterial spasm following subarachnoid haemorrhage: evidence against a major involvement of 5-hydroxytryptamine in the production of acute spasm. British Journal of Clinical Pharmacology, 6, 203-215.

Boullin, D. J., Hunt, T. M., and Rogers, A. T. (1978b). Models for investigating the aetiology of cerebral arterial spasm: comparative responses of the human basilar artery with rat colon, anococcygeus, stomach fundus and aorta, and guinea-pig ileum and colon. British Journal of Pharmacology, 63, 251-257.

Boullin, D. J., and Mohan, J. (1977). Effects of (+) and (-) - propranolol on the responses of the human isolated basilar artery to cerebrospinal fluid obtained from patients with subarachnoid haemorrhage and cerebral arterial spasm. British Journal of Clinical Pharmacology, 4, 27-31.

Boullin, D. J., Mohan, J., and Grahame-Smith, D. G. (1976). Evidence for the presence of a vasoactive substance (possibly involved in the aetiology of cerebral arterial spasm) in cerebrospinal fluid from patients with subarachnoid haemorrhage. Journal of Neurology, Neurosurgery, and Psychiatry, 39, 756766.

Buckell, M. (1964). Demonstration of substances capable of contracting smooth muscle in haematoma fluid from certain cases of ruptured cerebral aneurysm. Journal of Neurology, Neurosurgery, and Psychiatry, 27, 198-199.

Du Boulay, G. H. (1963). Distribution of spasm in the intracranial arteries after subarachnoid haemorrhage. Acta Radiologica Diagnosis, 1, 257-266.

Du Boulay, G. H., Symon, L., Ackerman, R., Dorsch, D., Kendall, B. E., and Shah, S. (1973). The reactivity of the spastic arteries. Neuroradiology, 5, 37-39.

Echlin, F. A. (1965). Spasm of basilar and vertebral arteries caused by experimental subarachnoid hemorrhage. Journal of Neurosurgery, 23, 1-11.

Echlin, F. A. (1968). Current concepts in the etiology and treatment of vasospasm. Clinical Neurosurgery, 15, 133-160.

Echlin, F. A. (1971). Experimental vasospasm, acute and chronic, due to blood in the subarachnoid space. Journal of Neurosurgery, 35, 646-655.

Gabrielsen, T. O., and Greitz, T. (1970). Normal size of the internal carotid, middle cerebral and anterior cerebral arteries. Acta Radiologica Diagnosis, 10, 1-10.

Horton, E. W. (1972). Prostaglandins. In Monographs on Endocrinology, vol. 7. Edited by F. Gross, A. Labhart, M. Lipsett, T. Mann, L. Samuels, and J. Zander. Springer Verlag: New York.

Hunt, W. E., and Hess, R. M. (1968). Surgical risk as related to time of intervention in the repair of intracranial aneurysms. Journal of Neurosurgery, 28, 14-19.

Nielsen, K. C., and Owman, C. (1971). Contractile response and amine receptor mechanisms in isolated middle cerebral artery of cat. Brain Research, 27, 33-42.

Radü, E. W., and Du Boulay, G. H. (1976). Paradoxical dilatation of the large cerebral arteries in hypocapnea in man. Stroke, 7, 569-572.

Ramwell, P. W., and Shaw, J. E. (1966). Spontaneous evoked release of prostaglandins from cerebral cortex of anesthetised cats. American Journal of Physiology, 211, 125-134.

Raynor, R. B., McMurtry, J. G., and Pool, J. L. (1961). Cerebrovascular effects of topically applied serotonin in the cat. Neurology (Minneapolis), 11, 190-195.

Simeone, F. A., and Finall, P. (1975). Mechanisms of contractile response of cerebral artery to externally applied fresh blood. Journal of Neurosurgery, 43, 37-46.

Starling, L. M., Boullin, D. J., Grahame-Smith, D. G., Adams, C. B. T., and Gye, R. S. (1975). Responses of isolated human basilar arteries to 5-hydroxytryptamine, noradrenaline, serum, platelets and erythrocytes. Journal of Neurology, Neurosurgery, and Psychiatry, 7, 650-656.

Weir, B., Grace, M., Hansen, J., and Rothberg, C. (1978). Time course of vasospasm in man. Journal of Neurosurgery, 48, 173-178.

Wilkins, R. H., Wilkins, G. K., Gunnels, J. C., and Odom, G. L. (1967). Experimental studies of intracranial arterial spasm using aortic strip assays. Journal of Neurosurgery, 27, 490-500.

Yamamoto, Y. L., Feindel, W., Wolfe, L. S., Katoh, H., and Hodge, C. P. (1972). Experimental vasoconstriction of cerebral arteries by prostaglandins. Jour nal of Neurosurgery, 37, 385-397.

Zervas, N. T., Kuwayama, A., Rosoff, C. B., and Salzman, E. W. (1973). Cerebral arterial spasm: modification by inhibition of platelet function. Archives of Neurology (Chicago), 28, 400-404. 